Article

\title{
Co-Creation for Social Innovation in the Ecosystem Context: The Role of Higher Educational Institutions
}

\author{
Richa Kumari ${ }^{1,2}$, Ki-Seok Kwon ${ }^{3}{ }^{10}$, Byeong-Hee Lee ${ }^{1,2}$ and Kiseok Choi ${ }^{1,2, *}$ \\ 1 Department of Science and Technology Management Policy, University of Science and Technology, Daejeon \\ 34113, Korea; richa.kumari08@ust.ac.kr (R.K.); bhlee@kisti.re.kr (B.-H.L.) \\ 2 National Science and Technology Information Service (NTIS) Center, Korea Institute of Science and \\ Technology Information (KISTI), Daejeon 34113, Korea \\ 3 Department of Public Policy, Hanbat National University, Daejeon 34158, Korea; kiseok@hanbat.ac.kr \\ * Correspondence: choi@kisti.re.kr; Tel.: +82-42-869-1723
}

Received: 19 October 2019; Accepted: 25 December 2019; Published: 30 December 2019

check for updates

\begin{abstract}
This study examined the role of Higher Educational Institutions (HEIs) in promoting, creating, and sustaining social innovation. Recently, HEIs have extended their contribution beyond the traditional function of teaching and research to perform in socio-economic problem-solving. Considering the increasing trends of higher education involvement in social innovation practices, this study tries to examine the tools such as learning processes and systemic thinking approach that could be helpful to align the function and responsibilities of HEIs towards social innovation. The objective is to develop a theoretical understanding of the "co-creation for social innovation" concept and to understand the functions and activities of HEIs that can contribute to this process. To promote co-creation for social innovation, HEIs should actively encourage collaborative learning tools that focus on open platforms for collective action and systemic change that help them to engage with society and strengthen their collaboration with social actors. Different activities such as mutual learning and knowledge diffusion using a transdisciplinary approach, technology-based learning and collaboration, and relational transformation are key enablers that can promote social innovation.
\end{abstract}

Keywords: problem-solving; critical reflection; knowledge integration; social learning; systemic thinking

\section{Introduction}

There has been an increasing interest in understanding and expanding the role of Higher educational institutions (HEIs) for social innovation to address complex societal challenges $[1,2]$. Recently, social innovation, emerged as one of the top institutional agendas in European Union (EU) policy process and appeared in various EU strategies such as relaunched Libson Strategy and Europe 2020 strategy [3]. The growing trends of social innovation initiatives in the international arena have made the topic highly important. However, the key issue for social innovation in HEIs is to integrate social innovation in the function and working model of HEIs. The rigid institutional environment and lack of flexibility to adapt as per the changing social context have reduced the effectiveness of HEIs in social innovation initiatives. To improve the efficiency and effectiveness, HEIs require a more flexible environment where they can transform to improve the attributes and functions and to work more responsible towards society. Currently, HEIs are facing immense pressure to continuously enhanced their role with the fast-changing society to cope with the changing complexity of the enivironment and to respond to the changing social needs. Most of the existing literature on the changing role of HEIs in society highlights the economic contribution and wealth creation perspective of HEIs, where they perform various market-oriented activities such as technology transfer and creation of knowledge-based enterprises through spin-off that promotes economic growth and 
regional development [1,4]. The current entrepreneurial model and third mission focuses on active university-industry participation and technology commercialization activities are mainly limited to their economic role in society $[4,5]$. However, these studies have undervalued the societal engagement of HEIs where they serve as a primary role in bringing social change and shaping the culture and values for future society [5]. The new role of HEIs in social value creation can only be achieved when societal needs can be integrated into HEI activities, and knowledge generated can be used to solve real-life societal challenges. To manage the prevailing challenges and to improve the engagement of HEIs in social innovation practices require an understanding of an integrated approach that leads towards the redesigning and transformation in different levels of processes and functions of HEIs that can improve their capacity for social innovation [6].

Considering the institutional theory perspective, Cai and Liu [7] explored the role of the university as an institutional entrepreneur [7] and highlights actor-driven activities of the university to show how changing the institutional conditions helps the university to improve their performance and to foster regional innovation $[5,7,8]$. The concept of an institutional entrepreneur focuses on the role of HEIs as a change agent which participates in the designing of a particular institutional arrangement through involving different strategies (organizing sufficient resources and mobilizing resources and power) to enact the institutional changes [7-9], and the new role makes HEIs more socially responsible. Merton et al. [10] examined the impact of changing of curriculum (in two US universities) and found that implementation of changed learning processes and curriculum was influenced by how well the changes in learning processes are associated with the arrangements and culture of the institutions, which directly have an impact on the success of innovation [10,11]. In another study on educational system transformation, Furst-Bowe [12] strongly suggests the need for a system thinking approach for changing the HEIs' educational programs, learning processes, strategy, and management [12]. The study emphasized when the innovation leaders, administrators, and researchers use a system thinking approach in governing and transforming institutions; the system thinking improves the pace and efficiency of working.

In order to create successful innovation, HEIs depend on its social networking capabilities such as how they collect resources, facilitate the knowledge dissemination process, and identify opportunities by forming social ties [11,13], thus increasing legitimacy for collective action and social innovation process. Social innovation in HEIs usually comes as a consequence of collective action and collaboration with institutional actors of the innovation ecosystem [14,15], low level of collaboration reduce the chances of co-development and co-creation of social innovation (CoSoI). Thus, it is important to understand the ways by which HEIs can enhance their networking capabilities to facilitate co-creation of social innovation.

To fill the gap between the current capabilities and status of HEIs and in order to fulfill emerging goals of changing society, it is important to examine the changes to improve the capabilities of HEIs to create and facilitate social innovation. Thus, the paper aims to develop understanding by examining and exploring different ways by which HEIs can improve their capabilities and capacity to enhance the opportunities for social innovation learners to participate in social innovation practices. This aspect focuses on two sub-questions: 1. How HEIs can incorporate different levels of changes to re-establish and reorganize their processes, activities and institutional action plan to improve their capacity and capabilities? The second question is 2 . How these changes are aligned with the role of HEIs to bring social change and transform society. The paper further aims to find out how innovation in learning processes and the systemic thinking approach can support and encourage the participation of HEIs in CoSoI process? This question considers role of HEIs in the innovation ecosystem to facilitate CoSoI which depends on networking and formation of social capital aspects.

Considering the various efforts to improve the capacity and to enhance the role of HEIs in innovation process, this paper proposes a framework how the changes in the learning models, improvements in curriculum programs, and the use of systems thinking approach can be linked with the contribution of HEIs in the social innovation process. This paper is structured as follows: Section 2 highlights the social innovation concept and outlines the steps required in co-creation for social innovation. Section 3 presents research methods and process. Section 4 elaborates about developing 
CoSoI capabilities through learning and system thinking approach. In Section 5, we discuss the transformations in the educational system. Section 6 presents proposition and recommended action plan and lastly, discussion and conclusion are presented in Section 7.

\section{Literature Review}

\subsection{Social Innovation as an Emerging Context}

Nowadays, society is facing new problems and grand challenges (environment destruction, social exclusion, aging, energy security, etc.), which are complex, interconnected, and multidisciplinary in nature and almost impossible to solve without the active and direct participation of actors of society and citizens. The complex interconnectivity of the problems has driven society towards social innovation initiatives that require critical thinking and cooperation that can guide the co-creation of new ideas or solutions to provide sustainability in society. According to The Bureau of European Policy Advisors (BEPA), social innovation is social in its means and ends which provide collective empowerment to people, meet their social needs, and drive social change [16]. Recently, social innovation has been increasingly evident in policy areas and projects of development organizations as a means to solve emerging societal problems. However, the idea and the notion of social innovation is still weakly conceptualized due to various definitions and lack of comprehensive theoretical foundation [17-21]. These definitions (Table 1) indicate the involvement of social aspects as an important feature and the innovation process is often bottom-up and context-specific approach [14]. Mulgan et al. [20] pointed out that working on social innovation depends on meeting the effective demands and supply together the idea production and diffusion of knowledge require proper strategies and adaptation to support the combination of demands and supply to achieve social impact [20]. Moulaert [22] conceptualizes social innovation as an outcome of actions which should lead to an effective way to bring improvements in social structure and relationship, and also can bring empowerment in society $[14,22]$. The new ideas that emerge as a consequence of social innovation provide an effective way to meet social goals by affecting (creating new or altering existing) relationships among the engaged stakeholders [23-25]. The improved or new relations in the social innovation process are based on trust and understanding rather than status and position and create a supportive environment that challenges and replaces the dominant power structure and institutions [26]. Thus, the key aspects of social innovation are:

- learning and knowledge exchange process,

- collaboration and change in relation,

- major actors and organizations involved in the process,

- change in social interaction and relations, encompass new ways of knowing and doing,

- collective empowerment and social change,

- development of new ideas and action to meet the demands,

- effective solution to address societal problems,

- sustainability to the outcome.

Table 1. Definition and stages model of the social innovation process.

\begin{tabular}{ccc}
\hline Authors & Stage1 & Stage 2 \\
\hline Mulgan et al. 2007 [21] & development of new ideas or activities or new approaches & to meet societal goals \\
\hline Herrera 2015 [27] & measurable initiatives & generate social value \\
\hline Jørgensen 2018 [28] & design co-creation system changing & alters the perception, behavior and social structures \\
\hline Phillis et al. 2008 [19] & novel solution value generation & an effective and sustainable solution to society \\
\hline Pol and Ville 2009 [29] & new ideas & quality and quantity of life \\
\hline Moulaert 2013 [22] & outcome of actions & empowerment \\
\hline $\begin{array}{l}\text { Bureau of European Policy } \\
\text { Advisors (BEPA) 2010 [16] }\end{array}$ & innovation social to their means and ends & empowering people and drive social change \\
\hline
\end{tabular}




\subsection{Ecosystem Concept of Social Innovation}

The ecosystem of social innovation allows the facilitation of a network of actors that interact and inter-relate in a variety of forms to co-create social innovation [30-33]. The ecosystem structure is dynamic and not limited to any geographical or industrial boundary and can evolve at any level in response to the actor's interaction to co-produce innovation. In these ways, it is unlike the system organization, which is static and geographically bounded. The collaborative structure of the ecosystem has agility in the environment and because of this ability of the actors to enjoy self-sustaining governance networks [34]. The social innovation ecosystem is characterized by complex interactions among a variety of stakeholders (actors) and their components, and the ecosystem aims to support technology development and innovation [35]. Multi actor perspective of the ecosystem and their connection helps to develop new ideas and solve societal problems. In the recent setting, the process of innovation is no longer seen as linear but as the unforeseeable product that a system generates by a nonlinear iterative process and increasingly relies on interaction and integration among the actors in the network [36,37]. The ecosystem concept provides a complete framework for socio-economic development, in which actors with diverse backgrounds and perspectives collectively work to improve the environment to make it favorable to innovation [38-41].

The framework of the innovation ecosystem is predominantly suitable for the creation of social innovation, where innovation follows a bottom-up approach that embraces the inclusion of society [42,43]. In the context, actors and supporters of the ecosystem must leverage the multifaceted system of interaction in rapidly changing environments. Moreover, the components of the system like policies, governance, financial, and social structure should create an environment and culture to support the system. HEIs play an important role in promoting the culture of trust and learning that reduces the conflict between partners. The knowledge exchange between HEIs and the community in the ecosystem brings positive change in society and promotes social innovation.

\subsection{The Context of Co-Creation for Social Innovation}

The co-creation is an important factor in the development of social innovation in the ecosystem framework which promotes the complex interaction of actors and citizens in the creation of new ideas. Co-creation is the core of the social innovation process encourages actors to integrate knowledge and assets, which can provide long-term benefits to society [44-46]. The idea of co-creation came from the business-and-service economy, in which co-creation is referred to the participation of the end-user with the business firms or service providers to co-create value (customers in service-dominant (S-D) logic), and the process is considered very cost-effective and time-saving [47,48]. S-D logic proposes that co-creation is a co-operative and dynamic process that involves the consumers in value creation. However, the concept of co-creation has not been widely explored in knowledge and innovation areas where it can be implied from the ecosystem perspective and can allow various actors to participate in innovation creation to co-create innovation. In a social-innovation context, the complex societal challenges demand the integration of knowledge and ideas and the collective approach of various innovation actors. Moreover, resources and capabilities (human and financial resources; knowledge, empowerment) are limited in individual organizations, so co-creation is a prerequisite for social innovation. EU Social Innovation-Driving Force of Social Change (SI-Drive) projects consider around 1005 cases in social innovation confirmed that co-creation and empowerment are two general features of all sorts of social innovation [46]. The means of collaboration, co-creation, and power shift during resource integration primarily determines the modes and approaches of social innovation.

The co-creation in the social domain involves citizens and civil society in designing and implementing the process in society. Voorberg, Bekkers, and Tummers [23] developed a framework of how citizens could be involved in the various co-creation process; citizens act as the initiator (co-initiate), as a co-designer and as implementors (implement public services). In the majority of cases, citizens participate in the co-implementation process, and the involvement of citizens in any of the co-creation process produces valuable outcomes [45]. To understand the co-creation for social 
innovation, we adopted Young Foundation principles and processes which serve as a foundation for CoSoI [49]. The principles and processes are based on the social innovation community (SIC) experimentation projects that aim to create a supportive environment for social innovation in Europe and beyond [49]. The four phases of co-creation of social innovation can be described as:

1. Prepare-understanding of challenges and problems and provide time to think about all possible solutions, team building, and capacity building),

2. Co-define-define the challenges, engagement of new stakeholders, co-defining the process),

3. Co-create-connect with similar challenges, resources for pilot work, a collective creation of solutions,

4. Implement-application and testing of the solution.

Based on the co-creation process stated above, we developed the CoSoI process to better understand the concept in the social innovation area. CoSoI can be broadly understood as a four-stage process (Figure 1). The first step of the process is to identify the societal needs, demands, and challenges which is important to define the existing problems. This stage is the same as the preparation phase main aim is to develop capacity and core team. The second step is to recognize the resource capabilities of different actors and to map stakeholders. This step is about co-defining the challenges that use a collaborative and open approach to better frame the challenges. For example, the SIC project identified and defined many local and complex challenges of Europe related to urban redevelopment, immigrant and refugee integration, public health, etc. and shared different ideas and solutions to solve these problems [49]. The third step explores knowledge diffusion, mutual learning, and resource integration activities and is identical to the co-create phase which focuses on the collective creation of solutions. In the fourth step, actors jointly utilize and exploit the knowledge and resources to create novel ideas and put those ideas into action. The implementation phase is related to the practical application of ideas to test the solution. In all steps, active and real participation of the community with key authorities at the local level is an important key for the successful social innovation process [50].

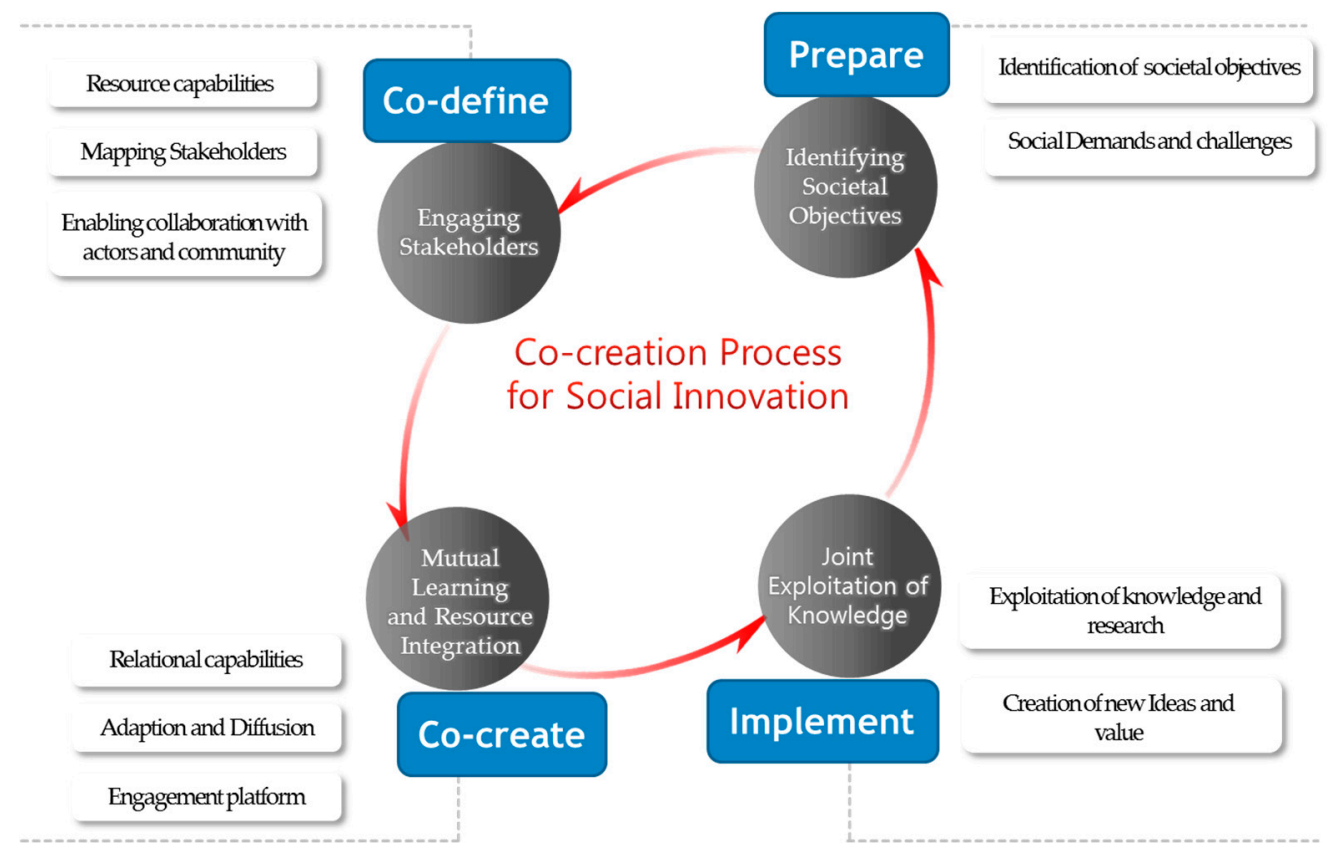

Figure 1. Four stages of Co-Creation for the Social Innovation Process. Source: adapted from the Young Foundation [49].

Co-creation activities among actors rely on the resource capabilities of other actors; the networking and relationships between embedded actors determine the diffusion of knowledge, and integration 
of resources [51]. Moreover, relational capabilities to interact with external partners transform the social relations by redistributing resources and power among the actors. An actor with superior relational capabilities can interact better than other actors with partners, and thus has superior access to knowledge and resources, and can thus enhance the co-creation process. This diffusion of knowledge and research by integration and transformation of social relations, governance, and power structure are the basic components of social innovation [52], and the process presents a new solution to attain sustainability in society [53].

\section{Research Method and Process}

The main purpose of the research is to find the way through which HEIs can participate in co-creation of the social innovation process. For the study, we used the Web of Science (WoS) core collection database to extract the documents. The search was conducted using the keyword: "social innovation" and "higher education" or "university in the title, abstract or keywords (TS = Topic) to find the relevant articles. As a result of the search, we found 67 publication documents. Out of 67 documents, only 41 publications were available in English. In the next stage, we checked for duplicate articles and also did a manual screening of title and abstract of these 41 documents to find the relevance as our search criteria; we excluded two articles as duplicates. Furthermore, after the manual screening of title and abstract, we removed nine records that were either not related to higher education or does not discuss the concept of social innovation in education perspective. Finally, we downloaded 30 articles for our systemic review. We checked key concepts and research trends used in these studies by analyzing the author's keyword (Appendix A). Finally, these 30 publications were selected for the literature survey and were used to build a model for HEIs to participate in social innovation. In addition to the above documents, we also reviewed the European Union social innovation project reports to gain better insight into the topic.

\subsection{Framework for HEIs to Participate in CoSoI}

The engagement of HEIs in the social innovation process is challenging for several reasons. First, HEI is considered as a change-resistant organization [54]. The institutional culture, legacy, and bureaucratic environment slow down evolution and make them resist change. Second, since social innovation has no clear standard definition, the concept uses a broad variety of expressions and approaches. Third, in the context of HEI contribution to social innovation, there is no specific framework and guidelines on how HEIs should contribute to the social innovation process. Benneworth [55] found HEIs' emphasis on teaching and research activities over place-based innovation that confines their role in dealing with social innovation. The restrictions and challenges in institutional structure and function create a gap in the pathway of HEIs for successful implementation of social innovation; HEIs, therefore, require proper planning, strategies, and evolution to be involved in the process of social innovation.

HEI evolution for the social innovation process has been investigated under two conventional bodies in the literature. One focuses on the process of institutional adaptation of HEIs towards changing environmental challenges [56] and the other emphasizes the internal characters of HEIs [57]. The literature covers both external (system) and internal (institutional) structures and function of HEIs that affects their capability to innovate and to serve the societal challenges and describes multiple level change in the structure and function of HEIs that include the change in structure, governance, and educational curriculum [58], change in norms and values of the institution [41,59], and changes that would improve the quality of interaction and collaboration. With the systemic review process, we identified some useful theories and concepts that could be helpful for HEIs to initiate necessary changes and to improve their participation in social innovation. We suggest internal (institutional) and external (ecosystem) level changes are needed in HEIs to facilitate the social innovation process as shown in the framework (Figure 2). 


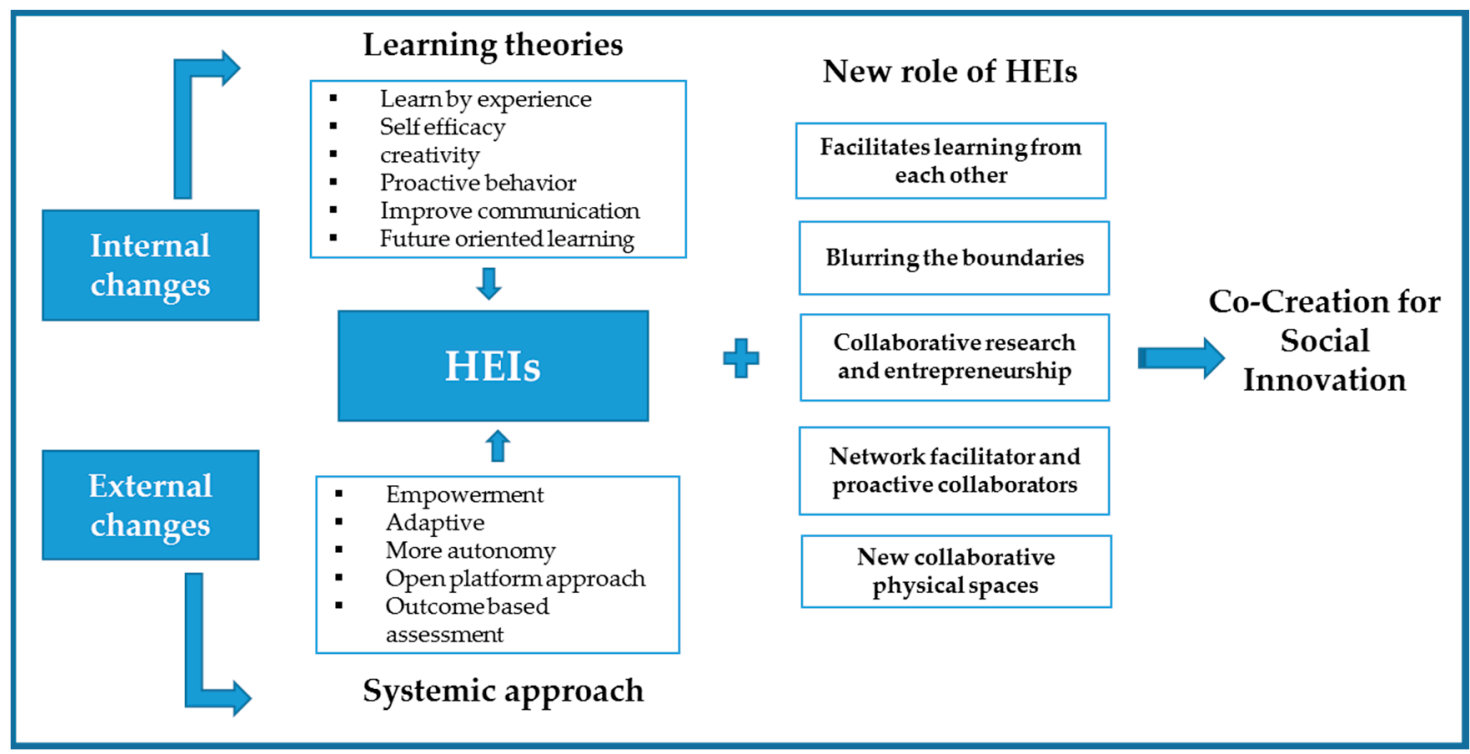

Figure 2. Framework model for HEIs in CoSoI.

The institutional changes can be explained under the institutional entrepreneurship theory that explores the role of HEIs as a change agent who supports the factors and environments necessary to initiate such changes and actively participate in implementing those changes. Changes in institutional setting reinforce the innovation in teaching and research practices to increase the participation of learners in social innovation initiatives. Similarly, system change theory focuses on the understanding of the organization as a system and focus on the interconnectedness of components which enhances the working efficiency. Whether these changes are made at an institutional or system level, such changes are mostly influenced by the decision of key individual actors, academic leaders, or department leaders who play an important role in the development of the innovation process. These people play a crucial role as a social innovation leader in various social innovation projects. In many cases, deans of universities were found to play a key role in driving innovation [60]. In other cases, the head of a department, teachers, researchers, and students can have a leading role who create and run new social enterprises by spin-offs. In ecosystem environments, there can be the other key actors outside the academic settings, local government leaders, bureaucrats, and business professionals can be included as innovation leaders as per their ability to create a new vision, the power to influence the decision and practical capabilities to lead the projects and to make innovation happens.

Many HEIs have developed these changes through innovating the learning environment and introducing new approaches that help learners to gain knowledge and skills necessary to facilitate social innovation. The OECD, Centre for Educational Research and Innovation (CERI) report [61] discussed various ways by which HEIs can engage with society. HEIs can become involved with citizens to help them to define and analyze their problems and can provide knowledge, consultancy, resources, physical spaces, and financial support to the community to assist in societal development. Social innovation and sustainability mission is strongly incorporated in many universities of South America and Europe which improves the contributions of these universities in tackling societal challenges [62]. The involvement of HEIs in CoSoI requires a reassessment of the organizational system and reconsidering our approach towards new knowledge processing that can bring innovation. Higher education, therefore, needs to extend its scope in facilitating new learning processes and experience that requires a disruptive innovation model to facilitate these changes.

\subsubsection{Embedding Social Innovation in Education (Learning Theories)}

To facilitate CoSoI, it is important to consider the learning methods that can develop new skills and the capacity to bring transformation and behavior modification to social innovation. The designing 
of learning processes could be used as an effective strategy for organizational development as well as to develop an interaction between HEIs to external actors [63]. Here, we identified the various learning processes from our systemic literature review on WoS data that can help to stimulate the process; Alden Rivers, Nie, and Armellini [64] identified the importance of different skills, behavior associated with the notion of changemaker and argued that designing education model for social innovation should be based on the understanding of outcome of the designed approach and the adoption of pedagogical praxis that supports and facilitates the designing and learning process $[64,65]$. The study conceptualized the different conception of changemaker (AshokaU) to develop the related skills, behavior, and attributes across the disciplines at the University of Northampton. The five different conceptions were found under changemaker concepts, for using this concept (1) as university strategy, (2) as critical thinking and problem solving approach, (3) for enhancing employability, (4) for social betterment, and (5) for personal transformation. These conceptions provide the basis to formulate a strategy for change in attributes and behavior for CoSoI.

The different learning processes such as transformative learning [66-68], (emphasizes on change in thoughts, perceptions, and actions through critical reflection), social learning (focuses on the learning through social interaction and participation), and critical learning [69] (learning process that opens up a new lens of perception based on critical reflection developed through social contextual experiences) are essential for developing competence to understand the context and co-operate with a variety of partners involved in the innovation process. Mezirow [67] recognized that transformative learning involves an important aspect of learning in adulthood which provides adults with a new point of view to see the world as a result of the perception of their own past experiences [67]; the adult learning is largely understood as a means of improvement of the well-being of society [70]. The knowledge and reflection achieved from experiences can help to develop analytical capabilities to deal with future societal challenges.

The learning process is important for the development of social and practical skills that are an opportunity to recognize and articulate the underlying theories and assumptions in their current practical approach, and could lead to a better understanding of problems. The outcome-based learning approach provides a way for assessment and developing the praxis to keep a balance between theoretical and practical approaches. Designing a social learning approach in the educational curriculum helps learners to change their attitudes and behavior towards societal problems and support them in creating social innovation $[54,71]$. This learning process focuses on the transformation of cognitive structure and behavior for human development and can develop a more shared knowledge between the partners. Critical reflection is a key mechanism of the learning that could be useful to place-based learning experiences and learning through social interaction which are considered as crucial components to the transformative capacity of HEIs for social innovation $[63,65]$. These learning processes could deliver new ideas through shared understanding.

This project-based learning process involves principles and approaches of action learning where a learner involves the creation of knowledge by collective activity and develops the solution by working on the real problems [72]. This process of learning by doing is a critical and holistic approach to traditional theory-based teaching. These learning processes involve the rigorous approach of developing the solution by understanding the context and relations and by taking action on the idea and then reassessing and refining the methods [73]. Similarly, introducing the analytical research practices such as action based research (defined as research methods that helps to systematically analyze the problems and help to develop practical solutions to address those problems quickly and efficiently) is seen as beneficial for the CoSoI process. Hence, this process helps to develop visions that can attain complex challenges and lead pathways to sustainable solutions.

The key elements of transformative learning as defined by Taylor [68]:

1. Focus on individual own experience as the main source for transformation,

2. Critical reflection,

3. Understanding of context, 
4. Valuing social relation,

5. Communication with the self and with others,

6. Future-oriented and holistic approach.

The adoption of novel learning processes by HEIs is critical for the institutional environment. These learning processes allow students and academicians (or learners) to participate in real-life challenges and prepare them to think critically (or search for) innovative ideas [74], and at the same time make them responsive to the solutions. Learning at a collective level through shared understanding and actions provides an opportunity to engage in more analytical discussion and approach societal issues [75]. At the institutional level, these learning processes provide a strong environment and mechanism to HEIs to expand their internal capacity and help them to build a relationship with external partners. HEIs require a value-based strategy that can guide their learning and teaching to bring institutional change and can enhance their impact on society. HEIs mission should reflect the purpose and value of the organization. The use of learning processes as a pedagogical strategy could provide empowerment and can drive social change.

In addition to innovation in learning processes, HEIs introduce different innovative and entrepreurship programs in curricula that provide opportunities to students and academicians to participate in various entrepreneurial activities and teach them with skills and knowledge to come up with novel business ideas and solutions. Such entrepreneurial ideas have supported many new social and business ventures and creation of new start-ups. Entrepreneurial experience nutures students with confidence and risk taking abilities and prepares them to better participate in addressing grand social challenges through social entrepreurship.

\subsubsection{Systemic Thinking Perspective for Organizational Change and for Strengthening the Collaboration}

In the ecosystem context, HEIs have been considered as a key organization in bringing social change and development by improving the organizational effectiveness and by strengthening the interaction and collaboration with other stakeholders. We reviewed and elaborated on the system thinking concepts and approach as a pedagogical framework [76] to highlight the characters that could be applied for the improvement of higher education institutions in the co-creation of the social innovation process. The system thinking approach provides a holistic understanding of the system as a whole and provides the ability to identify the components of a system, their processes, and interconnectedness within the system [77]. Bertalanffy [77] was the pioneer on system thinking, explains the approaches of viewing the problem as a whole, and emphasizes more on the interrelation of the components of a system rather than components itself [78]. Seddon [78] compared a traditional management approach (command and control) with a systemic thinking approach in managing the business and public services and believes that a systemic approach would lead to optimization within a system and provide benefits like lower cost, high efficiency, and better service quality as compared to a command and control management approach. The basic underlying concept of systemic thinking is adopted and compared with the approach with traditional educational organizations and functions (Table 2). In HEIs, systemic thinking can help students to visualize them as part of a large system and provide a better understanding of how-to bring changes to improve effectiveness in the institution and their co-related actions. Applying the systemic approach is also useful to bring complex and apparently disparate issues together and provide an understanding of every aspect of the issue and their impact on a variety of domains [79]. Thus, this systemic approach can help students to develop and implement solutions.

The use of a system thinking approach in recognizing the context and interrelationship among actors can guide to a framework that can enhance their behavior in the CoSoI process [80]. Fullan [81] emphasized that most of the HEIs fail in innovation as they have not understood how to develop system thinking in action. The incorporation of a system thinking approach in teaching and learning facilitates innovation as this approach involves activities such as brainstorming models, shared vision, and 
learning in the team. A systemic thinking approach produces strategies and environments that nurture learning (mutual learning, situational learning, learning as a perception), effective communication and encourages collaboration; all these components are desirable to improve the performance in CoSoI [82]. Dhukaram et al. [83] urged that the use of technology and ICT for learning and training in the system can be useful for developing solutions to complex problems in less time. Moreover, in many universities, a systemic approach is used to design technical and engineering education that involves an outcomes-based approach to curriculum development, and the assessment and evaluation process based on results [84] can improve the innovative capacity. The systemic thinking approach allows HEIs to make changes on various components (multilayer transition) of education system including a change in hardware (computers, equipment, and devices), software (operating system and other software), role changing (bottom-up approach, student role in project-based learning), services, finance, management, and process change, regulations and law, etc. [83]. The systemic thinking approach is particularly beneficial to address wicked problems and grand challenges of the 21st century that require a variety of actors and the use of systemic perspective involved towards practical, social-based learning and adaptive approach. Thus, the systemic thinking approach can be very useful to improve HEIs capacity in bringing societal transformation and development.

Table 2. Comparison between the traditional approach and the system thinking approach.

\begin{tabular}{ccc}
\hline & Traditional Approach & System Thinking Approach \\
\hline Outlook & $\begin{array}{c}\text { Top-down } \\
\text { (focus on to officers' perspective) }\end{array}$ & $\begin{array}{c}\text { Bottom-up (focus on user), } \\
\text { Outside-In }\end{array}$ \\
\hline Decision making & $\begin{array}{c}\text { Isolated, } \\
\text { No integration with work }\end{array}$ & $\begin{array}{c}\text { Integrated with work, } \\
\text { Work-based learning }\end{array}$ \\
\hline Assessment Methods & Traditional Assessment & Outcome-based and Project-based assessment \\
\hline $\begin{array}{c}\text { Methods of teaching } \\
\text { and learning }\end{array}$ & Obligatory, Extrinsic motivation & Intrinsic motivation \\
\hline Management approach & Closed Within the organization & $\begin{array}{c}\text { Open platform, Based on co-operation and } \\
\text { partnership, social learning }\end{array}$ \\
\hline & Source: Created by author, Adapted from [78].
\end{tabular}

\section{Developing CoSoI Capabilities through a Learning and Systemic Thinking Approach}

The use of learning processes and a systemic thinking approach in HEIs requires re-evaluation and revision of knowledge creation and a dissemination approach that can increase their contribution to CoSoI $[85,86]$. Learning and systemic adaptation involve various mechanisms through which HEIs can improve the capacity and capabilities of co-creation for social innovation. The co-creation aspects focus on collaboration and social interaction which can bring integration of knowledge/experiences and resources. The learning and systemic thinking process involves various activities such as knowledge sharing, collective research, and experimentation and critical thinking and reflexivity which transform the capacity of HEIs towards CoSoI $[63,86]$. These processes reshape the structure and relationship which involves a change in the power structure and redefine the collective meaning, which finally results in a change in attitudes, behavior, knowledge, and skills. Social learning and a project-based learning approach in teaching and curricula are used to develop critical thinking, independent problem-solving skills as well as working in a team. Furthermore, the systemic approach allows the development of multiple viewpoints to understand a problem and provide a holistic approach to decision-making.

\subsection{Knowledge Sharing and Collective Experimentation}

Knowledge sharing and experimentation in a social context is the most prominent way through which HEIs participate in social innovation activities. The literature review highlights the benefits of a collective approach to learning and experimentation which facilitates knowledge sharing and diffusion within and across the networking platform [87]. HEIs can extend their scope of knowledge production to a collaborative learning platform which is important to prepare learners as critical 
thinkers. The new learning processes such as project-based learning encourage learners to learn while doing and experimenting to develop their capabilities [88]. Collaboration, critical reflection, and creative thinking are a few key components of learning that can foster knowledge exchange activities between partners and play an important role in empowering society. During the process, social innovation learners learn from their own past experience of success or failure and alter or redesign the alternatives to get the desired action [63]. Networking and collaboration formed through the social learning process form a sustained interaction among actors to work together in order to find solutions to shared problems.

In addition, the incorporation of learning methods (social learning, learning by doing) as a teaching strategy to teach students to value social relationships and changes their ways of managing, doing, and seeing things. The new perspective encourages their capacity to understand and co-operate with a wide variety of actors as collaboration based on social relation provides a more effective problem-solving approach than communication as it provides a mutually accepted solution that is sustainable. The knowledge spillover effects stimulate technology innovation and have a positive impact on local communities. Furthermore, the exploitation of knowledge outside the academic setting in an open environment increases the possibilities to solve real-world problems and encourage social innovation practices $[87,88]$.

\subsection{Transforming Capabilities}

Creating new and innovative capabilities is another way through which learning processes support the co-creation of social innovation activities. According to Ottaviano [89], capabilities refer to abilities to use the processes (business) in order to mobilize its resources and to attain the desired innovation outcome. Capabilities can be a collection of learning capabilities (knowledge, skills, competency), technological, financial, social, and organizational capabilities towards the innovation goals. For example, technological capabilities such as abilities to produce novel ideas and develop the idea into products are key to innovation [90]. Compared to technology and product innovation, social innovation focuses on transformative skills and empowerment in order to find solutions for social challenges and demands. HEIs use various strategies and processes to manage organizational effectiveness and to improve institutional capabilities that focus more on creating public values instead of economic benefits and providing fertile ground for CoSoI. Learning theories and system thinking approaches create new capabilities and improve the existing ones that allow HEIs to adapt to the changing environment, and simultaneously facilitates social innovation [91]. Moreover, improvement in the capabilities of HEIs provides a better understanding of the process and supports the integration of new practices in the education system to deliver social change and facilitate CoSoI. Thus, it is believed that the improvement in HEIs capabilities is positively related to the co-creation of social innovation.

\subsection{Evaluating and Reflecting}

Critical reflection and evaluation are an important part of social innovation learning processes. Actors not only learn from the past reflection but evaluate the experiences to formulate better strategies. The critical reflection process identifies the deep-rooted assumption about society and individual relationships with society and brings cognitive changes. The alteration in underlying attitudes and beliefs and improves their thinking process to innovate and value social relations. The evaluating and reflecting process further influences the dominance and leadership structure of institutions. The new leadership structure based on trust and mutual relations in social context improves the transformative capacity for social change and promotes $\mathrm{CoSoI}$ in the long run. The learning processes further encourage the distribution of responsibilities between the actors and disperse the leadership from dominance organization to multiple organizations. This perspective helps to reduce the cognitive gap among engaged partners and support the continuous exchange of ideas and value [92]. Thus, it is important to support critical reflection and encourage evaluation through learning and systemic 
thinking approaches that can lead to transformation at different levels and can enact a collaborative approach to bring more desirable solutions for the society.

\section{Transformation in an Educational System}

These learning processes and systemic approaches bring transformation in the educational system and institutions where HEIs can use them to create public value. These approaches can change future perspectives and will promote new models in education and research that are based on:

1. Interdisciplinary research and new learning models,

2. Action-based research and entrepreneurship education,

3. New collaborative physical spaces.

\subsection{Interdisciplinary Research and New Learning Models}

The emergence of new courses and interdisciplinary research fields in learning processes and curricula have blurred the boundaries between disciplines. The introduction of new technology and research areas (biotechnology, nanotechnology, robotic technology, and other digital technologies) have also blurred the borders between basic science and applied research field [93-95], as these interdisciplinary technology fields require collaborative approaches between both science and engineering disciplines [96], and are useful to tackle complex problems of society. The convergences of different areas have an important implication on society and entail a learning approach that requires contribution and collaboration among different actors. The new fields educate on interdisciplinary thinking and skills to provide a better understanding of disciplinary methods across the fields to foster innovation. The new variety of interdisciplinary research areas provides the ability to think beyond the boundaries of a particular discipline, and encourages innovative culture and values co-creation. The technology areas also suggest an integrative approach and provide innovative solutions to problems and facilitate the co-creation of social innovation.

These changes have given rise to new educational institutions such as corporate universities, consortium, and online universities, etc. The rise of new actors like corporate university and consortium provides an open platform for business and academia intending to produce new products and services or improve the existing one. In addition, businesses and corporate universities help in the integration of the practical side of learning with theoretical balance and provide more funding opportunities and responses from the market, thus improving the innovative capabilities of higher education institutions. In addition, the rise of new learning models like Massive Open Online Courses (MOOC) and learning modes such as distance learning, e-learning have come as a future model in the education system. The new digital and virtual learning methods can deliver cheap or even free education to many students at a time [97]. The digital technologies support social innovation processes that demand an open environment and decentralization, in which knowledge can be produced in the societal context with the involvement of diverse groups of actors [98].

\subsection{Action-Based Research and Entrepreneurship}

The action-based research is a key component through which actors can learn and foster social innovation practices. Action-based research includes four major phases: planning (problem definition), acting (implementation of the strategic plan), observing (perceiving and evaluating the action), and reflecting (critical reflection on the whole process, helps them to gain a better understanding of issues and problems. The action-based research provides more systematic and holistic ways in technology development.

HEI involvement in entrepreneurship allows them to participate in various market-oriented activities without leaving behind academic values. Their participation in businesses provides them the ability to respond with complex surroundings with greater autonomy. Entrepreneurial activities can maintain the self-sufficiency and autonomy of institutions, and generate both economic and social 
benefits. In addition, entrepreneurship is important for the growth and innovation that converts novel ideas and new knowledge to successful innovation (products and services), which is necessary to gain a competitive advantage and improve their connection with local community [99-101]. To respond to changing research needs and societal technology challenges, HEIs should actively participate in various research and entrepreneurial activities that facilitate technology development and commercialization by obtaining patents, then licensing them and spinning-off companies [102-107]. The rise of entrepreneurial universities will help to better serve these functions in the future.

\subsection{Rise of New Concepts of Collaborative Spaces}

Social innovation focuses on the active involvement of citizens in the generation of public value [108]. The engagement of HEIs in social innovation encourages academicians and students to deliver a variety of social services by participating in community-development activities or service-learning [106]. The concept of transformative learning and systemic thinking uses educational practices to bring innovative and sustainable social changes. This concept can enable HEIs and other engaged actors to work on new ideas for social change and to create social impact. The European Union's (EU's) Transformative Social Innovation Theory (TRANSIT) project from 2014-2017 was set to develop a theory that focuses on the function of co-creation in social innovation [45]. The project emphasized on requirements of physical spaces (Table 3) like "Science shop", "Living lab" or "Desis $\mathrm{Lab}^{\prime}$, which HEIs can use to provide a collaborative platform to engage stakeholders for knowledge exploration and mutual learning and help them to perform their activities outside the academic setting in the societal context [28]. Several other educational organizations and universities provide different interactive spaces, such as Hackerspace (focus on electronic and computer programing) and Fab Lab (workshop space with set tools) that promote sharing of facilities for co-creation and co-production of knowledge [109]. The societal value generated by such facilities brings a transformation that directly or indirectly influences society. These spaces facilitate co-operation between HEIs and society, and translate the university knowledge in response to community knowledge needs. They then use this knowledge to improve research and education, thereby empowering both of the actors.

Table 3. New concepts of physical spaces in social innovation.

\begin{tabular}{|c|c|c|}
\hline Type of Association & Supporting Activities & Examples \\
\hline $\begin{array}{l}\text { Community Workshop } \\
\text { Hackerspaces and Fab Labs }\end{array}$ & $\begin{array}{ll}\text { - } & \text { Sharing of physical spaces, tools or other items } \\
\text { - } & \text { Interactive knowledge exchange and learning } \\
\text { - } & \text { Sharing different forms of knowledge, } \\
\text { practices, information }\end{array}$ & $\begin{array}{l}\text { European Union (EU) universities, } \\
\text { University of Sussex, United Kingdom } \\
\text { MIT's Center for Bits and Atoms }\end{array}$ \\
\hline Living Knowledge Science Shop, & $\begin{array}{ll}\text { - } & \text { University's co-ordination with civil society } \\
\text { - } & \text { Community-based research } \\
\text { - } & \text { Knowledge exchange for co-creation }\end{array}$ & $\begin{array}{l}\text { United Nation (UN) establishes } 17 \text { academic Impact Hubs } \\
\text { for SDGs }\end{array}$ \\
\hline Ashoka & $\begin{array}{l}\text { - Collaborate with HEIs and universities } \\
\text { - } \quad \text { Financial and networking support for } \\
\text { social entrepreneurship } \\
\text { Changemaker Campus to support culture and } \\
\text { practices of social innovation }\end{array}$ & $\begin{array}{l}45 \text { Colleges and universities ( } 37 \text { in US) } \\
\text { Such as Northeastern university } \\
\text { Arizona state university } \\
\text { Cornell University } \\
\text { Hanyang University Korea (First East-Asian changemaker } \\
\text { campus) }\end{array}$ \\
\hline Impact Hub & $\begin{array}{ll}\text { - } & \text { Building social entrepreneurship community to } \\
\text { bring impact } \\
\text { - } & \text { Support social and business innovation } \\
\text { - } & \text { Provide co-working spaces for co-creation } \\
\text { - } & \text { Knowledge Mobilization Idea cultivation }\end{array}$ & $\begin{array}{l}\text { Around } 95 \text { local Impact Hubs across } 5 \text { continents and more in } \\
\text { the process of making }\end{array}$ \\
\hline
\end{tabular}




\section{Proposition Based on Reseach Question and Recommended Action Plans}

\subsection{Proposition Based on Discussing Research Questions}

This paper aims to discuss the following problem statements and research questions:

Q1: How can HEIs improve their capabilities and capacity that can increase opportunities for social innovation learners to engage in different activities related to CoSoI and can enhance their participation in bringing societal change?

HEIs adopt different learning models and a systemic thinking approach that provides stages for the development of social innovation and manages the action towards successful innovation. For example, project-based and collective experimental learning includes more place-based learning methods that offer an opportunity to learners to upgrade their individual and social skills towards innovation. The key elements of all the learning models are based on critical reflection and rational thinking that encourages moderation in previous assumtions and mind frame. HEIs also critically analyzes and evaluates these learning models and provides feedback which is important to improve the effectiveness of the strategy and is helpful in redesigning the process based on reflection and outcome.

Q2: In a multi-actor innovation ecosystem, how can the learning activities and systemic thinking approach support HEIs to participate in the co-creation of social innovation? What are the roles played by HEIs in facilitating multi-actors for the CoSoI process?

In innovation ecosystem, HEIs play a pivotal role as a network facilitator and mediator that improve the connectivity between the actors to stimulate innovation. Learning processes in HEIs such as social learning focuses on mutual respect and valuing relations that are the core element of networking and collaboration. The learning processes provide necessary skills that allow HEIs to participate in critical functions of maintaining the relationship and collaboration between stakeholders, and in the formation of interfaces among education, research, and society to transfer the benefits of innovation to the larger community. In addition to learning processes, systemic thinking is also important for HEIs to expand their capabilities and to develop multiple competencies useful for CoSoI.

Social innovation learning stresses the need for an open engagement platform that enables the integration of resources to facilitate co-creation. This platform helps to integrate resources and capabilities and to manage collaboration by orchestrating actors to promote successful innovation. HEIs proactive engagement in open networks and collective innovation improves knowledge mobility and disseminates knowledge to businesses and society. Furthermore, HEIs can provide mutual ground and supportive infrastructure that enables the mobilization of funds to sustain the value generation process and consequent innovation.

Based on two major research questions, the following propositions are developed to test the hypothesis for future research:

- In the case of CoSoI practices, which requires learning for problem-solving skills based on critical reflection and evaluation to create and transform capabilities results formulation of an effective strategy for social innovation.

- Co-creation in the innovation ecosystem requires collective action and collaboration that embrace social relation, incorporating learning in social context cultivate new skills, knowledge, and capabilities and enhance knowledge sharing and network connectivity.

- The networking and collaboration through learning processes also influence power relations and leadership of dominance institutions based on trust developed during learning. This reduces the differences in attitudes, values, and perspectives.

- Learning processes along with the systemic approach is important for transforming capabilities and long-term organizational changes that are required to foster societal innovations by changing attributes and behavior as well as organizational culture. 


\subsection{Recommended Action Plan Based on Proposed Framework}

Figure 3 suggests an action plan based on our proposed framework. Figure 3 outlines the action plan for HEIs and other actors like society and policymakers to support and encourage CoSoI. These action plans can serve as guidelines for them to improve capacity and social innovation learning. For example, HEIs need to change traditional learning methods and support an environment conducive to social innovation learning such as experimentation based learning and transformative learning that can motivate students towards social innovation initiatives. Management and entrepreneurial education provided by HEIs encourage the risk-taking abilities of students for social entrepreneurship, which requires proper platform and funding support from other partners. Similarly, citizens should be aware of the educational programs and policies to get optimum benefits. Implementation of social innovation requires a mutual process where all partners are equally involved in the co-creation of innovation.

Society

Figure 3. Recommended action plan based on framework.

\section{Discussion}

This study presents a conceptual framework on how HEIs can facilitate CoSoI through a learning and systemic approach and highlights the key mechanism underlying the process. An integrated table showing an overview of the process and functions of HEIs in CoSoI is tabulated in Table 4. Firstly, the paper elaborates on the different steps in the process of CoSoI which includes problem identification, engaging relevant actors for co-creation, mutual learning, and knowledge exchange among the actors which results in resource integration and change in relations, and the final step is joint exploitation of knowledge by actors for successful innovation. These steps in the CoSoI process provide an understanding of the process and evaluate the changing impact. To fulfill the goal of CoSoI, different types of learning processes and a system thinking approach are elaborated that can encourage social innovation capabilities and can empower the actors to improve their access to funds and resources, and can promote collaboration. The learning processes reviewed in the paper focuses on a set of underlying features like critical reflection, transforming capabilities, and evaluation that helps learners to transform their skills and abilities. These collective learning processes in social settings provide the necessary skills and competence to co-create and implement successful innovation. 
Table 4. Overview of process and function of HEIs in Co-creation for Social Innovation.

\begin{tabular}{|c|c|c|c|c|}
\hline \multirow{2}{*}{$\begin{array}{c}\text { Objective } \\
\begin{array}{c}\text { HEIs Function in } \\
\text { the Process }\end{array}\end{array}$} & \multicolumn{4}{|c|}{ Achieve Social Demands and Challenges through the "CoSoI" Process } \\
\hline & $\begin{array}{l}\text { Knowledge Sharing and } \\
\text { Collective Learning }\end{array}$ & $\begin{array}{l}\text { Collaborative Research } \\
\text { and Entrepreneurship }\end{array}$ & $\begin{array}{l}\text { Network Facilitator and } \\
\text { Proactive Collaborator }\end{array}$ & $\begin{array}{l}\text { New Collaborative } \\
\text { Physical Spaces }\end{array}$ \\
\hline $\begin{array}{l}\text { Channel of } \\
\text { Contribution }\end{array}$ & $\begin{array}{l}\text { Education and Skill Development } \\
\text { Mutual Learning } \\
\text { Knowledge Diffusion } \\
\text { Awareness for Social Problems } \\
\text { Virtual Learning Methods } \\
\text { ICT and Digital based Solution } \\
\text { Transdisciplinary Education } \\
\text { Science and Engineering Balance }\end{array}$ & $\begin{array}{l}\text { Basic and Applied Research } \\
\text { Participatory Research } \\
\text { Action Learning } \\
\text { Licensing and Spin-Off } \\
\text { Technology Transfer } \\
\text { Business Incubation } \\
\text { Start-ups and Venture } \\
\text { Creation } \\
\text { Support Commercialization }\end{array}$ & $\begin{array}{l}\text { Mediator in Collaboration } \\
\text { Engagement Platform } \\
\text { Support Research } \\
\text { Integration } \\
\text { Orchestration of actors }\end{array}$ & $\begin{array}{l}\text { Service-learning } \\
\text { Increase openness and Open } \\
\text { Collaboration } \\
\text { Living Laboratories } \\
\text { Fab Lab }\end{array}$ \\
\hline Key Resources & $\begin{array}{l}\text { Professors, Students, } \\
\text { Knowledge, Facilities from Different } \\
\text { actors, Multidisciplinary Knowledge } \\
\text { Science Shop }\end{array}$ & $\begin{array}{l}\text { Students and Academician } \\
\text { Technician and Researchers } \\
\text { Joint Lab Support } \\
\text { DesisNetwork and Fab Labs } \\
\text { Technology Transfer office }\end{array}$ & $\begin{array}{l}\text { Integrated Knowledge, } \\
\text { Facilities and Equipment } \\
\text { Physical Space } \\
\text { (e.g., Hackerspaces) }\end{array}$ & $\begin{array}{l}\text { Professors, Students, } \\
\text { Researcher } \\
\text { Civil society }\end{array}$ \\
\hline
\end{tabular}

The learning processes used in the framework is based on knowledge sharing and a collective experimentation process which strengthen HEI capacity to serve with a broad range of responsibilities and support social innovation initiatives. Designing learning based on key components can provide direction and motivation to learners to initiate the social innovation process. In addition, it is important to combine a systemic approach with the learning processes that could be helpful to identify the organization as a system and emphasizes the interrelationship, arrangements, and response structures that come together to generate innovation and can bring value propositions to the wider society. In addition, both learning and a system change approach strengthened organizational abilities to research and entrepreneurship by supporting key mechanisms of network collaboration and resource exchange activities. Thus, HEIs are required to be innovative in educational methods and curricula redesigning which should be done at a regular interval considering the notion of social innovation.

The study is useful for several reasons and has policy implications at different levels. In general, the study provides an understanding and importance of co-creation in the social innovation process, which is useful in social innovation practices. Second, the framework outlines how HEIs can contribute to facilitating CoSoI through different learning processes and systemic change that can support the development of innovative capabilities. In addition, the paper provides a recommended set of action plans that can serve as guidelines for educational institutions, the public, and policymakers to better implement the process. Redesigning educational methods and restructuring of institutions based on systemic change can help students to improve their skills and reduce the gap between educators and learners to understand the process and action plan. Furthermore, redesigning and reevaluation of learning processes help policymakers to formulate effective policies that align with the mission and goals of social innovation education. For successful implementation of CoSoI, HEIs will require a conducive environment and regulation where they can enjoy enough autonomy, funding support, and improved transformative capabilities. This study is limited to theoretical and conceptual methods based on systemic literature review and the paper provides propositions that are developed to test the hypothesis in future empirical study to answer the research questions.

Author Contributions: This paper was written by R.K., K.-S.K., B.-H.L. and K.C., contributed in designing the study, developing the framework for the study, and interpreting the study results. All authors have revised and approved the final paper. All authors have read and agreed to the published version of the manuscript.

Funding: This research received no external funding.

Acknowledgments: This research was supported by the construction of the linkage system between National Science and Technology Information Service (NTIS) and the Science Technology Infrastructure project of the Korea Institute of Science and Technology Information (KISTI).

Conflicts of Interest: The authors declare no conflict of interest. 


\section{Appendix A}

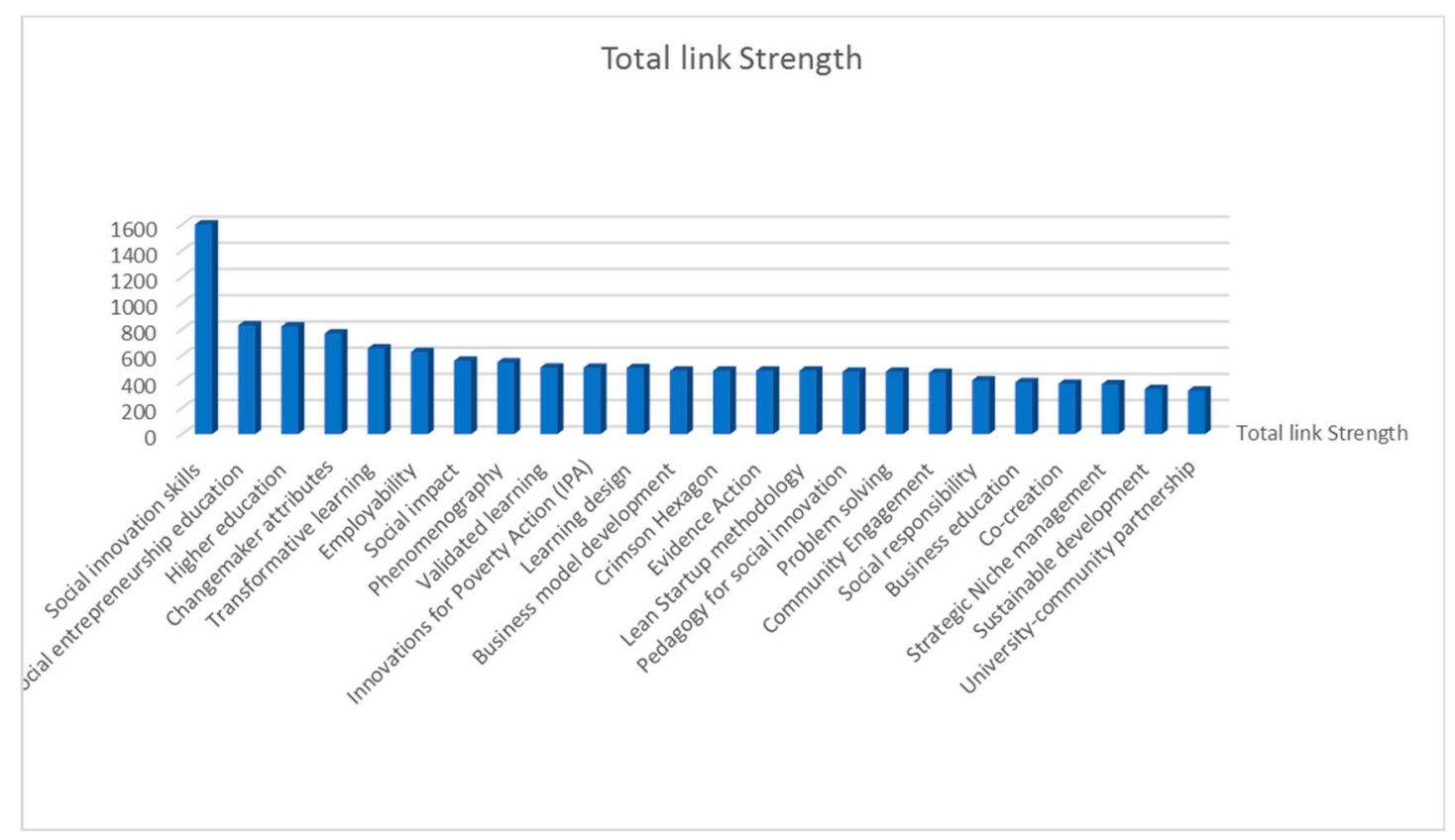

Figure A1. Keywords as per total link strength fromWoS author's keyword database.

\section{References}

1. Etzkowitz, H.; Leydesdorff, L. The dynamics of innovation: From national systems and "Mode 2" to a triple helix of university-industry-government relations. Res. Policy 2000, 29, 109-123. [CrossRef]

2. Mowery, D.C.; Sampat, B.N. Universities in national innovation systems. In The Oxford Handbook of Innovation; Fagerberg, J., Mowery, D.C., Nelson, R.R., Eds.; Oxford University Press: Oxford, UK, 2005; pp. 209-239.

3. European Commission. Entrepreneurship 2020 Action Plan: Reigniting the Entrepreneurial Spirit in Europe. Available online: https://eur-lex.europa.eu/LexUriServ/LexUriServ.do?uri=COM:2012:0795:FIN:EN:PDF (accessed on 12 September 2019).

4. Etzkowitz, H. Evolution of the Entrepreneurial University. Int. J. Technol. Glob. 2004, 1, 64. [CrossRef]

5. Cai, Y.; Liu, C. The entrepreneurial university as an institutional entrepreneur in the regional innovation system: Towards an analytical framework. In Examining the Role of Entrepreneurial Universities in Regional Development; Daniel, A.D., Aurora, A.C.T., Preto, T.M., Eds.; IGI Global: Hershey, PA, USA, 2018; pp. 133-156.

6. Shukla, D. Modeling systems thinking in action among higher education leaders with fuzzy multi-criteria decision making. Manag. Mark. Chall. Knowl. Soc. 2018, 13, 946-965. [CrossRef]

7. DiMaggio, P.J. Interest and Agency in Institutional Theory. In Institutional Patterns and Organizations; Zucker, L., Ed.; Ballinger: Cambridge, UK, 1988; pp. 3-22.

8. Cai, Y.; Liu, C. The entrepreneurial university as an institutional entrepreneur in regional innovation system development: The case of Tongji Creative Cluster in Shanghai. In Proceedings of the XIII Triple Helix International Conference 2015, Beijing, China, 21-23 August 2015.

9. DiMaggio, P.J.; Powell, W.W. The new institutionalism in organizational analysis: Introduction. In New Institutionalism in Organizational Analysis; University of Chicago Press: Chicago, IL, USA, 1991; pp. 1-38.

10. Merton, P.; Froyd, J.E.; Clark, M.C.; Richardson, J. A Case Study of Relationships between Organizational Culture and Curricular Change in Engineering Education. Innov. High. Educ. 2009, 34, 219-233. [CrossRef]

11. Hasanefendic, S.; Birkholz, J.M.; Horta, H.; Sijde, P.V.D. Individuals in action: Bringing about innovation in higher education. Eur. J. High. Educ. 2017, 7, 101-119. [CrossRef]

12. Furst-Bowe, J. Systems thinking: Critical to quality improvement in higher education. Qual. Approaches High. Educ. 2011, 2, 2-5.

13. Davidsson, P.; Honig, B. The Role of Social and Human Capital among Nascent Entrepreneurs. J. Bus. Ventur. 2003, 18, 301-331. [CrossRef] 
14. Avelino, F.; Wittmayer, J.; Pel, B.; Weaver, P.; Dumitru, A.; Haxeltine, A.; Kemp, R.; Jørgensen, M.; Tom, B.; Ruijsink, S.; et al. Transformative social innovation and (dis)empowerment. Technol. Forecast. Soc. Chang. 2019, 145, 195-206. [CrossRef]

15. Adner, R. Match your innovation strategy to your innovation ecosystem. Harv. Bus. Rev. 2006, 84, 98-107.

16. BEPA. Empowering People, Driving Change: Social Innovation in the European Union; Publications Office of the European Union: Luxembourg, 2010.

17. Mulgan, G. The Theoretical Foundations of Social Innovation; Palgrave Macmillan: London, UK, 2012.

18. Mulgan, G. The process of social innovation. Innovations 2006, 1, 145-162. [CrossRef]

19. Phills, J.A.; Deiglmeier, K.; Miller, D.T. Rediscovering social innovation. Stanf. Soc. Innov. Rev. 2008, 6, 34-43.

20. Mulgan, G.; Tucker, S.; Ali, R.; Sanders, B. Social Innovation: What It Is, Why It Matters and How It Can Be Accelerated; Said Business School: Oxford, UK, 2007.

21. Mulgan, G. Ready or not: Taking innovation in the public sector seriously. In Nest Provocation 03; NESTA: London, UK, 2007.

22. Moulaert, F.; Mehmood, A.; MacCallum, D.; Leubolt, B. Social Innovation as a Trigger for Transformations-The Role of Research; Publications Office of the European Union: Brussels, Belgium, 2017. [CrossRef]

23. Voorberg, W.; Bekkers, V.; Tummers, L. Embarking on the social innovation journey: A systematic review regarding the potential of co-creation with citizens. In Proceedings of the Paper for the IRSPM Conference, Prague, Czech Republic, 10-12 April 2013.

24. Murray, R.; Caulier-Grice, J.; Mulgan, G. The Open Book of Social Innovation; The Young Foundation: London, UK, 2010.

25. Sörensen, E.; Torfing, J. Enhancing collaborative innovation in the public sector. Adm. Soc. 2011, 43, 842-868. [CrossRef]

26. Haxeltine, A.; Avelino, F.; Pel, B.; Dumitru, A.; Kemp, R.; Longhurst, N.; Chilvers, J.; Wittmayer, J.M. A Framework for Transformative Social Innovation (TRANSIT Working Paper \# 5). TRANSIT: EU SSH.2013.3.2-1; Grant Agreement No.: 613169. 2016. Available online: http://www.transitsocialinnovation.eu/content/original/Book\%20covers/Local\%20PDFs/240\%20TRANSIT_ WorkingPaper_no5_TSI\%20framework_Haxeltine\%20et\%20al_November2016_AH041116.pdf (accessed on 30 December 2019).

27. Herrera, M.E.B. Creating competitive advantage by institutionalizing corporate social innovation. J. Bus. Res. 2015, 68, 1468-1474. [CrossRef]

28. Jørgensen, M.S. Social Innovation as Spaces for Co-Creation; Center for Design Innovation Og Bæredygtig Omstilling: Copenhagen, Denmark, 2018.

29. Pol, E.; Ville, S. Social innovation: Buzz word or enduring term? J. Socio-Econ. 2009, 38, 878-885. [CrossRef]

30. Adner, R.; Kapoor, R. Value creation in innovation ecosystems: How the structure of technological interdependence affects firm performance in new technology generations. Strategy Manag. J. 2010, 31, 306-333. [CrossRef]

31. Oh, D.S.; Phillips, F.; Park, S.; Lee, E. Innovation ecosystems: A critical examination. Technovation 2016, 54, 1-6. [CrossRef]

32. Autio, E.; Thomas, L.D.W. Innovation Ecosystems: Implications for Innovation Management. In Oxford Handbook of Innovation Management; Dodgson, M., Gann, D.M., Phillips, N., Eds.; Oxford University Press: Oxford, UK, 2014; pp. 204-228.

33. Oksanen, K.; Hautamäki, A. Sustainable Innovation: A Competitive Advantage for Innovation Ecosystems. Technol. Innov. Manag. Rev. 2015, 5, 24-30. [CrossRef]

34. Smorodinskaya, N.; Russell, M.; Katukov, D.; Still, K. Innovation Ecosystems vs. Innovation Systems in Terms of Collaboration and Co-creation of Value. In Proceedings of the 50th Hawaii International Conference on System Sciences, Waikoloa Village, HI, USA, 4-7 January 2017.

35. Jackson, B.D.J. What Is an Innovation Ecosystem? 2011. Available online: http://erc-assoc.org/sites/default/ files/topics/policy_studies/DJackson_InnovationEcosystem_03-15-11.pdf (accessed on 21 September 2019).

36. Valkokari, K. Business, innovation, and knowledge ecosystems: How they differ and how to survive and thrive within them. Technol. Innov. Manag. Rev. 2015, 8, 17-24. [CrossRef]

37. Schaffers, H.; Turkama, P. Living labs for cross-border systemic innovation. Technol. Innov. Manag. Rev. 2012, 2, 25-30. [CrossRef] 
38. Pellikka, J.; Ali-Vehmas, T. Managing Innovation Ecosystems to Create and Capture Value in ICT Industries. Technol. Innov. Manag. Rev. 2016, 6, 17-24. [CrossRef]

39. Valkokari, K.; Seppänen, M.; Mäntylä, M.; Jylhä-Ollila, S. Orchestrating Innovation Ecosystems: A Qualitative Analysis of Ecosystem Positioning Strategies. Technol. Innov. Manag. Rev. 2017, 7, 12-24. [CrossRef]

40. Mercan, B.; Göktas, D. Components of Innovation Ecosystem: A Cross-Country Study. Int. Res. J. Financ. Econ. 2011, 76, 102-112.

41. Iivari, M. Exploring Business Models in Ecosystem Contexts. Ph.D. Thesis, University of Oulu, Oulu, Finland, 2016.

42. Salmelin, B. Engagement platforms and business modelling in Open Innovation 2.0 environments. In Open Innovation 2.0 Yearbook; European Union: Luxembourg, 2016; pp. 9-15.

43. Bramwell, A.; Hepburn, N.; Wolfe, D.A. Growing Innovation Ecosystems: University-Industry Knowledge Transfer and Regional Economic Development in Canada; Final Report to the Social Sciences and Humanities Research Council of Canada: Ottawa, ON, Canada, 2012.

44. Chin, T.; Yang, Y.; Zhang, P.; Yu, X.; Cao, L. Co-creation of Social Innovation: Corporate Universities as Innovative Strategies for Chinese Firms to Engage with Society. Sustainability 2019, 11, 1438. [CrossRef]

45. Voorberg, W.; Bekkers, V.; Tummers, L. Co-creation and Co-production in Social Innovation: A Systematic Review and Future Research Agenda. In Proceedings of the EGPA Conference, Speyer, Germany, 10-12 September 2014.

46. Oeij, P.R.A.; Van Der Torre, W.; Vaas, S.; Dhondt, S. Understanding social innovation as an innovation process. Report based on data from SI-Drive. In Social Innovation: Driving Force of Social Change; TNO: Leiden, The Netherlands, 2018.

47. Vargo, S.; Lusch, R. Evolving to a New Dominant Logic for Marketing. J. Mark. 2004, 68, 1-17. [CrossRef]

48. Prahalad, C.K. The concept of Co-creation: C.K. Prahalad in conversation with Sarah Powell, "Spotlight" Column Editor. Available online: https://www.emerald.com/insight/content/doi/10.1108/02580540410567256/ full/pdf?title=the-concept-of-cocreation-ck-prahalad-in-conversation-with-sarah-powell-spotlightcolumn-editor (accessed on 15 September 2019).

49. Nagore, M.; Bynon, R. How to Set Up a Process of Social Innovation; The Young Foundation: London, UK, 2018.

50. European Commission. Social Business Initiative: Creating a Favorable Climate for Social Enterprises. Available online: http://ec.europa.eu/internal_market/social_business/docs/COM2011_682_en.pdf (accessed on 18 September 2019).

51. Adner, R.; Kapoor, R. Innovation ecosystems and the pace of substitution: Re-examining technology S-curves. Strateg. Manag. J. 2016, 37, 625-648. [CrossRef]

52. Howaldt, J.; Kopp, R. Shaping social innovation by social research. In Challenge Social Innovation; Springer: Berlin/Heidelberg, Germany, 2012.

53. Schröder, A.; Krüger, D. Social Innovation as a Driver for New Educational Practices: Modernising, Repairing and Transforming the Education System. Sustainability 2019, 11, 1070. [CrossRef]

54. Blass, E.; Hayward, P. Innovation in higher education; will there be a role for "the academe/university" in 2025? Eur. J. Futures Res. 2014, 2, 41. [CrossRef]

55. Cunha, J.; Benneworth, P.S. Universities' contributions to social innovation: Towards a theoretical framework. In Proceedings of the Cities as Seedbeds for Innovation, Annual Conference of the European Urban Research Association (EURA), Enschede, The Netherlands, 3-6 July 2013.

56. Chatterton, P.; Goddard, J. The response of higher education institutions to regional needs. Eur. J. Educ. 2000, 35, 475-496. [CrossRef]

57. Kezar, A.; Eckel, P. The Effect of Institutional Culture on Change Strategies in Higher Education. J. High. Educ. 2002, 73, 435-460. [CrossRef]

58. Davis, S.N.; Jacobsen, S.K. Curricular integration as innovation: Faculty insights on barriers to institutionalizing change. Innov. High. Educ. 2014, 39, 17-31. [CrossRef]

59. Bariakova, D.A. Systematic Review of Social Innovation in Higher Education Systems as a Driver of Student Employability. In Innovate Higher Education to Enhance Graduate Employability-Rethinking the Possibilities; Routledge, Taylor \& Francis, UK Ltd.: Oxfordshire, UK, 2019. [CrossRef]

60. Cleverley-Thompson, S. The Role of Academic Deans as Entrepreneurial Leaders in Higher Education Institutions. Innov. High. Educ. 2016, 41, 75-85. [CrossRef] 
61. Centre for Educational Research and Innovation. The University and the Community: The Problems of Changing Relationships; OECD: Paris, France, 1982.

62. Crets, S.; Celer, J. The interdependence of CSR and Social Innovation. In Social Innovation-Solutions for a Sustainable Future; Osburg, T., Schmidpeter, R., Eds.; Springer: Berlin/Heidelberg, Germany, 2014.

63. Strasser, T.; Kraker, J.; Kemp, R. Developing the Transformative Capacity of Social Innovation through Learning: A Conceptual Framework and Research Agenda for the Roles of Network Leadership. Sustainability 2019, 11, 1304. [CrossRef]

64. Alden Rivers, B.; Nie, M.; Armellini, A. University teachers' conceptions of "Changemaker": A starting point for embedding social innovation in learning and teaching. In Proceedings of the 6th International Social Innovation Research Conference, York, UK, 1-3 September 2014.

65. Alden-Rivers, B. Social innovation education: Designing learning for an uncertain world. In Innovation and Entrepreneurship in Education; Emerald Group Publishing Limited: Bingley, UK, 2016; pp. 75-90.

66. Mezirow, J. Fostering Critical Reflection in Adulthood; Jossey-Bass: San Francisco, CA, USA, 1990.

67. Mezirow, J. On critical reflection. Adult Educ. Q. 1998, 48, 185-198. [CrossRef]

68. Taylor, E.W. Fostering transformative learning. In Transformative Learning in Practice: Insights from Community; Mezirow, J., Taylor, E.W., Eds.; Workplace, and Higher Education, Jossey-Bass: San Francisco, CA, USA, 2009; pp. 3-17.

69. Giroux, H.A. On Critical Pedagogy; Bloomsbury Publishing: London, UK, 2011.

70. Dirkx, J.M. Engaging emotions in adult learning: A Jungian perspective on emotion and transformative learning. New Dir. Adult Contin. Educ. 2006, 109, 15-26. [CrossRef]

71. Scharmer, O.; Kaufer, K. Leading from the Emerging Future from Ego-System to Eco-System Economies; B.K. Publishers Inc.: San Francisco, CA, USA, 2013.

72. Revans, R.W. The Origin and Growth of Action Learning; Chartwell Bratt: London, UK, 1982.

73. Dilworth, R.L.; Willis, V.J. Action Learning: Images and Pathways; Krieger: Malabar, FL, USA, 2003.

74. Huhtelin, M.; Nenonen, S. A Co-creation Centre for University-Industry Collaboration-A Framework for Concept Development. Procedia Econ. Financ. 2015, 21, 137-145. [CrossRef]

75. Halbe, J. Governance of Transformations towards Sustainable Water, Food and Energy Supply Systems-Facilitating Sustainability Innovations through Multi-Level Learning Processes. Ph.D. Thesis, Universitäty Osnabrück, Osnabrück, Germany, 2016.

76. Senge, P.M. The Fifth Discipline: The Art E Practice of the Learning Organization; Doubleday Business: New York, NY, USA, 1990.

77. Bertalanffy, L. General System Theory; George Braziller Inc.: New York, NY, USA, 1968.

78. Seddon, J. Freedom from Command and Control: A Better Way to Make the Work Work; Vanguard Education Ltd.: Buckingham, UK, 2003.

79. Porter, T.; Córdoba, J. Three Views of Systems Theories and their Implications for Sustainability Education. J. Manag. Educ. 2008, 33, 323-347. [CrossRef]

80. Dzombak, R.; Mehta, C.; Mehta, K.; Bilén, S. The Relevance of Systems Thinking in the Quest for Multifinal Social Enterprises. Syst. Pract. Action Res. 2013, 27, 593-606. [CrossRef]

81. Fullan, M. Leadership and Sustainability: System Thinkers in Action; Corwin Press: Washington, DC, USA, 2005.

82. Shaked, H.; Schechter, C. Seeing wholes: The concept of systems thinking and its implementation in school leadership. Int. Rev. Educ. 2013, 59, 771-791. [CrossRef]

83. Dhukaram, A.V.; Sgouropoulou, C.; Feldman, G.; Amini, A. Higher education provision using systems thinking approach-Case studies. Eur. J. Eng. Educ. 2016, 43, 3-25. [CrossRef]

84. Walther, J.; Radcliffe, D. Engineering education: Targeted learning outcomes or accidental competencies? In Proceedings of the ASEE Annual Conference \& Exposition, Chicago, IL, USA, 18-21 June 2006; pp. 18-21.

85. Vorley, T.; Nelles, J. (Re) Conceptualising the Academy: Institutional Development of and beyond the Third Mission. High. Educ. Manag. Policy 2008, 20, 119-135.

86. Lee, S.M.; Hwang, T.; Choi, D. Open innovation in the public sector of leading countries. Manag. Decis. 2012, 50, 147-162. [CrossRef]

87. Edwards-Schachter, M.E.; Matti, C.E.; Alcántara, E. Fostering quality of life through social innovation: A living lab methodology study case. Rev. Policy Res. 2012, 29, 672-692. [CrossRef] 
88. Boe, C.S. Have 21st Century Skills Made Their Way to the University Classroom? A Study to Examine the Extent to which 21st Century Skills Are Being Incorporated into the Academic Programs at a Small, Private, Church-Related University. Ph.D. Thesis, Gardner-Webb University, Boiling Springs, NC, USA, 2013.

89. Ottaviano, M.E. Assessing and Improving the Enablers of Innovation: The Development of an Innovation Capability Assessment instrument. Ph.D. Thesis, Swinburne University of Technology, Melbourne, Australia, 2004.

90. Hadjimanolis, A. The barriers approach to innovation. In The International Handbook on Innovation; Elsevier Science: Oxford, UK, 2003.

91. Chalmers, D.M.; Balan-Vnuk, E. Innovating not-for-profit social ventures: Exploring the micro foundations of internal and external absorptive capacity routines. Int. Small Bus. J. 2013, 31, 785-810. [CrossRef]

92. Vasin, S.M.; Gamidullaeva, LA.; Rostovskaya, TK. The Challenge of Social Innovation: Approaches and Key Mechanisms of Development. Eur. Res. Stud. J. 2017, 20, 25-45.

93. Cipolla, C.; Serpa, B.; Afonso, R. Design for social innovation between university and the broader society: A mutual learning process. Mix Sustentável 2017, 3, 109-118. [CrossRef]

94. Rosenberg, N.; Nelson, R.R. American Universities and Technical Advance in Industry. Res. Policy 1994, 23, 325-348. [CrossRef]

95. Mansfield, E.; Lee, J.Y. The Modern University Contributor to Industrial Innovation and Recipient of Industrial R\&D Support. Res. Policy 1996, 25, 1047-1058.

96. Zhu, C.; Engels, N. Organizational culture and instructional innovations in higher education: Perceptions and reactions of teachers and students. Educ. Manag. Adm. Leadersh. 2014, 42, 136-158. [CrossRef]

97. Jensen, A.A.; Krogh, L. Re-Thinking Curriculum for 21st-Century Learners: Examining the Advantages and Disadvantages of Adding Co-Creative Aspects to Problem-Based Learning. In Co-Creation in Higher Education; Chemi, T., Krogh, L., Eds.; Sense Publishers: Rotterdam, The Netherlands, 2017; pp. 1-14.

98. Masters, K. A Brief Guide to Understanding MOOCs. Available online: http://ispub.com/IJME/1/2/10995 (accessed on 27 September 2019).

99. Cai, Y. From an analytical framework for understanding the innovation process in higher education to an emerging research field of innovations in higher education. Rev. High. Educ. 2017, 40, 585-616. [CrossRef]

100. Baumol, W.J. The Free-Market Innovation Machine; Princeton University Press: Princeton, NJ, USA, 2002.

101. Schumpeter, J.A. The Theory of Economic Development; Harvard University Press: Cambridge, UK, 1934.

102. Moore, J.F. Predators and prey: A new ecology of competition. Harv. Bus. Rev. 1993, 71, 75-86.

103. Moore, J.F. Business ecosystems and the view from the firm. Antitrust Bull. 2006, 51, 31-75. [CrossRef]

104. Rucker Schaeffer, P.; Fischer, B.; Queiroz, S. Beyond Education: The Role of Research Universities in Innovation Ecosystems. Foresight STI Gov. 2018, 12, 50-61. [CrossRef]

105. Clark, B. Creating Entrepreneurial Universities; IAU Press-Elsevier: Oxford, UK, 2004.

106. Hong, W. Decline of the center: The decentralizing process of knowledge transfer of Chinese universities from 1985 to 2004. Res. Policy 2008, 37, 580-595. [CrossRef]

107. Youtie, J.; Shapira, P. Building an innovation hub: A case study of the transformation of university roles in regional technological and economic development. Res. Policy 2008, 37, 1188-1204. [CrossRef]

108. Singaraju, S.; Nguyen, Q.; Niininen, O.; Sullivan Mort, G. Social media and value co-creation in multi-stakeholder systems: A resource integration approach. Ind. Mark. Manag. 2016, 54, 44-55. [CrossRef]

109. Smith, A. Social Innovation, Democracy and Makerspaces. Available online: www.sussex.ac.uk/spru/ swps2017-10 (accessed on 11 September 2019).

(C) 2019 by the authors. Licensee MDPI, Basel, Switzerland. This article is an open access article distributed under the terms and conditions of the Creative Commons Attribution (CC BY) license (http://creativecommons.org/licenses/by/4.0/). 